\title{
Ensino de gramática: uma abordagem gerativa
}

\section{Teaching grammar: a generative approach}

Junia Lorenna da Silva'

\section{Resumo}

Este trabalho visa estabelecer uma aproximação entre pressupostos oriundos da Teoria Gerativa, de Noam Chomsky (a partir de 1957), e conceitos a ela correlatos, e o ensino de língua portuguesa, estabelecendo correlações entre pressupostos da teoria, tais como Aquisição de Linguagem, Gramática Universal (GU), Input, Argumento da Pobreza de Estímulo, Período Crítico e questões relacionadas ao ensino, e pesquisar como tais pressupostos podem vir a acrescentar possíveis soluções para os problemas e questões enfrentadas por professores com relação ao ensino de língua materna, além de propor reflexões sobre os métodos de ensino. A Teoria Gerativa desenvolvida por Noam Chomsky nunca se propôs ser uma teoria de ensino. Muitos foram os desdobramentos dessa teoria no âmbito das pesquisas sobre linguagem e mente, mas, ainda assim, é um desafio a relação entre o gerativismo e o ensino de línguas. Esta epistemologia da teoria gerativa é um ponto de partida para se discutir a natureza do conhecimento linguístico do falante. Vamos discutir como essa noção de linguagem pode contribuir para o ensino de língua escrita, e mostrar que aquisição e aprendizado são distintos, tendo por base os estudos de Carnie (2002) e Kato (2005), e que a relação entre ensino e L2 se dá através da L1. A literatura de ensino de L2 pode contribuir para o ensino da língua escrita no sentido de delimitar teoricamente, para o profissional, onde se dará o processamento mental do conhecimento por parte do aluno, facilitando, assim, a elaboração de material didático, objetivos e resultados a serem atingidos, e pesquisas que ampliem o entendimento de docentes sobre o papel dos dados de input na geração (output) de estruturas sintáticas dentro de uma dada variedade linguística. E, com base nas contribuições de VanPatten (2003), é preciso investigar ainda mais que tipo de dado é considerado relevante para que haja um input adequado aos objetivos escolares.

Palavras-chave: Ensino. Teoria gerativa. Input. Língua portuguesa.

\section{Abstract}

This work aims to establish a connection between assumptions from the Generative Theory of Noam Chomsky (from 1957), and concepts related to it, and the teaching of Portuguese, establishing correlations between assumptions of the theory, such as Language Acquisition, Universal Grammar (UG), Input, Poverty Stimulus Argument, Critical Period and issues related to teaching, and research how such assumptions may prove to add possible solutions to the problems faced by teachers regarding the teaching of the native language, and propose reflections on teaching methods. The Generative Theory developed by Noam Chomsky has never been proposed to be a
1 Mestranda do Programa de Pós-Graduação em Linguística da Universidade de Brasília (UnB). 
theory of teaching. Many were the developments of this theory in the context of research on language and mind, but the relationship between it and language teaching is still a challenge. This epistemology of generative theory is a starting point to discuss the nature of linguistic knowledge of the speaker. We will discuss how this notion of language can contribute to the teaching of written language, and we will show that acquisition and learning are different, based on the studies of Carnie (2002) and Kato (2005), and that the relationship between teaching and L2 is through L1. Literature about teaching of L2 can contribute to teaching of writing in order to define theoretically the mental processing of knowledge by the student, thus facilitating the development of teaching materials, goals and results to be achieved, and research about the role of input on data generation (output) of syntactic structures within a given linguistic variety. And, based on the contributions of VanPatten (2003), we need to investigate further what kind of data is considered important for the generation of an appropriate input for educational goals.

Keywords: Teaching. Generative theory. Input. Portuguese.

\section{Introdução}

Este trabalho visa estabelecer uma aproximação entre pressupostos oriundos da Teoria Gerativa, de Noam Chomsky (a partir de 1957), e conceitos a ela correlatos, e o ensino de língua portuguesa. Em outras palavras, a presente pesquisa pretende estabelecer correlações entre pressupostos da teoria, tais como Aquisição de Linguagem, Gramática Universal (GU), Input, Argumento da Pobreza de Estímulo, Período Crítico e questões relacionadas ao ensino, e pesquisar como tais pressupostos podem vir a acrescentar possíveis soluções para os problemas e questões enfrentadas por professores com relação ao ensino de língua materna, além de propor reflexões sobre os métodos de ensino. A Teoria Gerativa desenvolvida por Noam Chomsky nunca se propôs ser uma teoria de ensino. Muitos foram os desdobramentos dessa teoria no âmbito das pesquisas sobre linguagem e mente, mas, ainda assim, é um desafio a relação entre o gerativismo e o ensino de línguas.

O presente artigo está organizado da seguinte forma: inicialmente será apresentada a abordagem da teoria, suas propostas, afirmações e contribuições e, em seguida, será feita uma reflexão sobre a maneira como esses conceitos podem contribuir para uma melhoria na prática didática do professor de língua portuguesa do Brasil.

\section{A hipótese gerativista}

A Teoria Gerativa passou por uma série de desdobramentos e modificações até que atingisse o modelo mais recente, que é o Programa Minimalista. Contudo, trataremos mais propriamente da versão particular da Gramática Gerativa que é a Teoria de Princípios e Parâmetros. Os conceitos iniciais dessa teoria permanecem pertinentes. São eles: Aquisição da Linguagem, Gramática Universal (GU), Argumento da Pobreza de Estímulo e Período Crítico.

A análise do sistema linguístico, sob a luz dessa teoria, é feita com base na cognição do falante. Chomsky acreditava que as sentenças são geradas por uma série de procedimentos do subconsciente, porém, a Teoria Gerativa não se propôs ser uma teoria de neurologia. Com base no método descritivo, Chomsky considerou que há em cada ser humano uma Faculdade Inata de Linguagem, ou seja, a linguagem adquirida por um indivíduo encontrase pautada em um instinto humano que lhe é inerente. A esse estado inicial da Faculdade de Linguagem é dado o nome de Gramática Universal (GU).

Acredita-se que há em cada indivíduo um órgão responsável pela a aquisição de uma língua, mesmo que não se tenha chegado ainda à postulação de qual órgão é esse e se ele possui de fato uma realização espacial na mente do falante. A ideia de se ter um órgão da linguagem reafirma a postulação de Chomsky de que sua teoria é baseada em pressupostos de modularidade, isto é, há uma interligação entre vários setores da mente para que a linguagem se efetue. Acredita-se que haja um componente no cérebro, e possivelmente outros sistemas do corpo, especificamente dedicado à linguagem. Supõe-se, por exemplo, que a Área de Broca, região do cérebro responsável pelo processamento da linguagem, produção da fala e compreensão, seja uma das partes do cérebro envolvidas no uso da linguagem. Não necessariamente se espera, todavia, encontrar uma localização para a linguagem, pois ela é um sistema complexo, com propriedades e funções identificáveis. 
Se entendermos os princípios e parâmetros da linguagem, saberemos o que é o dispositivo de aquisição da linguagem. Há princípios que são universais a todas as línguas e há parâmetros que são específicos a elas. A criança, na medida em que entra em contato com um input linguístico, ou seja, com um dado sistema linguístico, vai fixando em sua mente os parâmetros específicos da língua com a qual está em contato. Quando esses parâmetros são fixados, tem-se uma língua. O dispositivo de aquisição da linguagem é algo que faz a mediação entre o estado inicial da faculdade da linguagem e os estados que ela pode alcançar. Para que o mapeamento das estruturas linguísticas de uma língua seja feito na mente do falante, ele precisa entrar em contato com uma dada língua, seja ela a L1 ou a L2. Esse contato dá-se através da exposição a um input linguístico.

Input, segundo Vanpatten (2003), é algum tipo de informação explícita sobre algo, é a linguagem que o aprendiz lê ou ouve que tem alguma intenção comunicativa, entendida como uma mensagem que o aprendiz é levado a considerar. O input é a base para a aquisição e existe dentro de um contexto comunicativo.

Dependendo do tipo de estímulo que a criança recebe, há modificação na sua $\mathrm{GU}$, e, portanto, haverá estados diferentes conforme o tipo de estímulo, ou seja, conforme o tipo de input. O sistema cognitivo da criança, no processo de aquisição da $\mathrm{L} 1$, recebe do ambiente, através do que ouve, inúmeros dados linguísticos e precisa de estímulo, num determinado momento da vida, para poder funcionar, mas há alguma variação no modo de funcionamento conforme o tipo de estímulo. É preciso haver certos tipos de estímulo para que o sistema funcione, e as formas desse estímulo, aparentemente, alteram seu modo de funcionamento.

Dentro da teoria gerativista, defende-se que há um Período Crítico para a Aquisição de Linguagem. Toda propriedade biológica que se conhece tem um período no qual precisa ser ativada. Depois desse período, a capacidade de ativação declina acentuadamente ou pode até desaparecer. "Há uma linha de corte para a capacidade de adquirir linguagem em torno de seis a oito anos e, provavelmente, uma outra linha de corte por volta da puberdade" (Vanpatten, 2003, p.34). Considerar a hipótese do período crítico restringe consideravelmente a capacidade de se adquirir uma língua. Quando a criança passa de certo estágio, até pode adquirir sua língua materna, mas essa aquisição se dará de forma mais dificultada.

Pensando dessa forma, é pertinente fazer uma ponderação a respeito da existência de um período crítico para aquisição da língua escrita, pois há uma margem de variação individual na aquisição de língua, seja L1 ou L2, em idade avançada. Porém, ainda não foi possível verificar qual o estatuto da língua escrita sob o ponto de vista cognitivo nem como ocorrem os processos mentais relacionados à aprendizagem dessa forma linguística.

$\mathrm{Na}$ próxima seção apresentarei uma distinção entre aquisição e aprendizagem; em seguida, relaciono questões de ensino de L2 às de ensino da norma padrão na escola.

\section{Aquisição vs aprendizagem}

Faz-se necessário estabelecer uma diferença entre aquisição e aprendizagem, pois faremos uso desses termos ao longo da exposição. Conforme Carnie (2002, p.14), um dos erros mais comuns é pensar que crianças e adultos aprendem uma língua, pois o conceito mais básico de uma língua é um conhecimento subconsciente. Isso implica dizer que aprender uma língua se baseia no conhecimento subconsciente já internalizado inconscientemente através da aquisição da L1. Os adultos e crianças não aprendem, de fato, uma segunda língua; aprendem uma segunda gramática e adquirem uma segunda língua. Não há aprendizado inconsciente, o que ocorre é que esse aprendizado é conscientemente mediado pelo conhecimento inconsciente.

Em seu artigo, Kato (2005) defende que a aquisição da gramática no Brasil, diferentemente do que ocorre em Portugal, assemelha-se à aprendizagem de L2. A autora aborda três hipóteses para essa afirmação. A primeira diz respeito ao processo de letramento que, segundo ela, recupera o conhecimento gramatical do indivíduo em alguma época passada do PB. A segunda diz respeito aos convênios culturais com Portugal que privilegiam a unidade linguística; portanto, o saber é pautado no conhecimento linguístico do falante português. E, por fim, a terceira, por ela defendida, diz que esse conhecimento se define como algo distinto das outras duas hipóteses.

Kato (2005) assume, sobre a aquisição de uma L2, que o acesso é indireto, via primeira gramática - a da lín- 
gua falada, no nosso caso, e defende a hipótese de que a gramática da L1 contém uma periferia marcada onde valores paramétricos opostos ao da gramática nuclear podem estar presentes, com caráter marcado, recessivo. Esses valores podem competir durante a escolarização em relação aos que se encontram definidos na gramática nuclear. A autora, com base em Chomsky $(1981,1986)$, defende que, quando todos os valores dos parâmetros estão selecionados como (+) ou (-), temos uma gramática nuclear, virtual, uma idealização, e a Língua-I de cada indivíduo é constituída de uma gramática nuclear e uma periferia marcada. Essa periferia, segundo Chomsky (1981),

pode abrigar fenômenos de empréstimos, resíduos de mudança e invenções, de forma que indivíduos da mesma comunidade podem ou não apresentar esses fenômenos de forma marginal (Kato, 2005, p.2).

Sobre a forma do conhecimento da criança brasileira antes da escolarização, Kato (2005) afirma que essa criança chega à escola com sua gramática nuclear definida, isto é, com todos os valores dos parâmetros selecionados, e exemplifica esta afirmação com dados do PB antigo que se caracterizava como uma língua típica de Sujeito Nulo (SN). Sobre a forma do conhecimento do letrado brasileiro, Kato (2005) afirma que, “[...] no processo do letramento, a escola procura recuperar as perdas linguísticas, uma vez que as inovações são apropriadas para a fala, mas não para a escrita" (KATO, 2005, p.4). E conclui que "[...] a gramática do letrado brasileiro, no que diz respeito a clíticos, não corresponde nem a uma gramática de um falante letrado do passado e nem à de um letrado português" (KATO, 2005, p.6). Com relação ao desenvolvimento do conhecimento da gramática da escrita, a autora defende que "[...] aprender a escrever para a criança brasileira é como aprender uma L2" (KATO, 2005, p.6), pois:

[...] as duas aprendizagens são socialmente motivadas e não biologicamente determinadas; nos dois casos, o início da aprendizagem começa, em geral, depois da idade crítica para a aquisição; o processo, nos dois casos, é essencialmente consciente; em geral, o processo nas duas “aquisições" é vagaroso e não instantâneo; nos dois casos, há mais diferenças individuais (KATO, 2005, p.6).

A autora, ao questionar-se se as teorias sobre a aquisição de L2 podem oferecer alguma contribuição, apresenta a literatura sobre a aquisição da gramática de L2 e suas hipóteses. A hipótese do não acesso à GU diz que:
[...] enquanto o aprendiz de L1 parte da Gramática Universal (GU) e atinge a Língua-I por seleção dos valores dos Parâmetros, o aprendiz de uma L2, com exceção do bilíngue simultâneo ou quase simultâneo, não tem acesso à GU, nem direto, nem indireto; a aprendizagem se dá através de um mecanismo multifuncional [...]. Dentro dessa hipótese, passou-se a distinguir o termo "aquisição" para L1 e "aprendizagem" para L2 (KATO, 2005, p.6).

A segunda hipótese diz que a aquisição de L2, para quem já adquiriu plenamente uma L1, se dá via acesso indireto à GU, através da L1. Sendo assim, com relação ao desenvolvimento do conhecimento da escrita, Kato (2005) conclui que há o acesso indireto à GU através da gramática da fala, e isso espelha melhor o tipo de conhecimento do letrado, ou seja, defende que escrita não é L2.

\section{0 ensino de gramática}

O ensino de uma língua possui uma natureza complexa, pois envolve conhecimentos didáticos, sociais, antropológicos, psicológicos e outros. No presente trabalho, não serão desconsiderados esses ramos do saber, mas não os abordaremos, todavia. Foca-se, com contribuições da teoria gerativa, discutir metodologias para o ensino de gramática.

Considera-se aqui que todo indivíduo que possui como língua materna o português brasileiro, ou qualquer outra língua, é, de certa forma, bilíngue. Muitos acreditam que os falantes do Brasil são bilíngues porque a diferença entre a oralidade e a escrita é muito grande. Para nós, a língua individual adquirida no lar, L1, corresponde aos usos e à compreensão que se tem nos contextos orais, e a escolarização acrescenta aos conhecimentos do falante uma variedade coletiva de língua que é mais frequentemente usada nos contextos escritos, porém a eles não se restringe. Sendo assim, muitos pensam, com base nesse distanciamento entre a oralidade e a escrita, que, na escola, se aprende uma segunda língua por se aprender a escrever, porém não é isso que acontece. A chamada L2 adquirida com a escolarização não diz respeito à escrita, mas sim a todo um conjunto complexo de relações novas a que o aluno não estava acostumado (tanto orais, quanto escritos), pois não interagia em contextos de língua padrão.

Posto isto, pode-se falar mais detalhadamente das principais contribuições da teoria gerativa para o "ensino" de português. (A palavra ensino está entre aspas porque, 
na realidade, não se ensina a língua portuguesa ao aluno, pois ele já possui em sua mente o sistema, ou seja, a gramática do português quando inicia sua escolarização). A primeira contribuição é esta de se olhar para o aluno como alguém que já detém a gramática do português. A gramática com que o aluno entra na escola, doravante chamada de GA (Gramática do Aluno), foi adquirida no seu lar através da sua exposição a um input linguístico. $\mathrm{O}$ professor precisa estar ciente desse importante fenômeno, pois, à medida que o aluno entra em contato com o input linguístico da L2 (gramática coletiva, a língua escrita), fará relações desta com a L1 aprendida no contexto doméstico, e é necessária essa relação.

Segundo VanPatten (2003), o foco principal de um aprendiz de L2 é o significado, logo, precisa compreender mensagens que estão codificadas linguisticamente em itens lexicais (palavras), sintaxe (estrutura da sentença), morfologia (flexão das palavras) e assim por diante. Ele faz conexões entre o significado e como o significado está codificado. Sendo assim, a aquisição de L2 na escola acontece como um produto da compreensão.

Nesse sentido, cabe ao professor de língua portuguesa ensinar ao aluno uma gramática que ele ainda não utiliza, a GP (Gramática Padrão), a partir de um estímulo à compreensão de sentenças na modalidade padrão de sua língua. Esta GP será aprendida à medida que o aluno é exposto a um tipo de input diferenciado daquele com que ele teve contato desde o seu nascimento. $\mathrm{O}$ input que precisa ser oferecido para que se adquira a L2 na escola precisa ser compreensível, não tendo relação com o sistema de regras: "Input para aquisição não é informação sobre a linguagem" (VANPATTEN, 2003, p.26).

É preciso que a escola baseie sua metodologia na forte consciência de que a língua portuguesa do Brasil apresenta modalidades diferenciadas de uso, e que a modalidade oral, adquirida da infância, compreende um uso e configuração específicos, diferente daqueles empregados pela modalidade padrão. Dizer que pessoas falam uma só língua certamente não é verdadeiro no Brasil, e creio que não seja verdadeiro em nenhum país. A criança, ao chegar à escola, começa a ter contato com a modalidade escrita de sua língua, que parece até se tratar de outra língua, diferente daquela que ela já sabe. Pensando dessa maneira, é possível afirmar que todo mundo cresce ouvindo várias línguas diferentes, pois as "variedades estilísticas", ou modalidades, assemelham-se, na verdade, a sistemas línguísticos. Logo, todos crescem num ambiente multilíngue.

Cabe questionar, portanto, de que maneira o input deve ser oferecido pela escola para que o aluno adquira a GP e que tipo de input é esse. Se nossos alunos saem das instituições de ensino despreparados para a produção textual, pressupõe-se que a escola não esteja oferecendo a eles o ensino adequado. É preciso repensar as atuais metodologias de ensino a fim de que o aluno tenha um desempenho linguístico eficaz.

A educação básica do Brasil é avaliada de acordo com o que o aluno consegue gerar em sua L2. Dessa maneira, surge outro importante conceito: output. Output é, conforme VanPatten (2003), qualquer coisa que emerge de outra; algo produzido propositalmente, ou seja, é a linguagem com significado que o aprendiz produz.

Assim como o input, o output precisa ter um propósito comunicativo, pois é produzido por aprendizes para expressar algum tipo de significado. Aprendizes de uma L2 pensam no que querem dizer e tentam pôr isso em prática selecionando palavras do léxico para expressar significados particulares. Quando escrevemos e pensamos, acessamos e produzimos output ao mesmo tempo.

A produção escolar precisa ser guiada por estratégias, pois aprendizes de L2 (língua escrita) acessam dois diferentes procedimentos: o primeiro, eles trazem da aquisição e o segundo, da apropriação da L2 enquanto está sendo desenvolvida. O que o aprendiz de L2 faz é reconstruir os procedimentos com as leis da L2 e suas restrições. Aprendizes de L2 embasam-se nas estratégias de produção de sua L1 quando eles não têm construídas as estratégias da L2 e têm de se comunicar na L2. Essa é uma estratégia comunicativa: um jeito de usar o que se sabe para se expressar quando não se consegue. O resultado é algo que soa como L2, mas tem a estrutura da L1.

Vanpatten (2003) aborda algo também pertinente para nossos trabalhos - a hierarquia implicacional. Ele afirma que, nesse contexto de aquisição de segunda língua, alguns procedimentos têm de estar postos antes de outros serem adquiridos. Sendo assim, o output é resultado de um engajamento do aprendiz com o input. O output tem um papel de negociar sentidos, encorajar outros processos que ajudam aprendizes a adquirir a língua. Diferentemente do input, o output não é dado para aquisição, porém, sem o input (procedimento semântico) 
não é gerado output (procedimento sintático). O output desempenha o papel de facilitador da aquisição. Fazer output força o aprendiz a articular melhor o input.

\section{Desdobramentos}

Procurei demonstrar nessa pesquisa, primeiramente, qual a noção de linguagem dada pela teoria gerativa. Essa epistemologia funcionou como ponto de partida para se discutir a natureza do conhecimento linguístico do falante. Em seguida, procurei discutir como essa noção de linguagem pode contribuir para o ensino de língua escrita. Mostrei que aquisição e aprendizado são distintos, tendo por base os estudos de Carnie (2002) e Kato (2005), e que a relação entre ensino e L2 se dá através da L1.

A literatura de ensino de L2 pode contribuir para o ensino da língua escrita no sentido de delimitar teoricamente, para o profissional, onde se dará o processamento mental do conhecimento por parte do aluno, facilitando, assim, a elaboração de material didático, de objetivos de ensino e de resultados a serem atingidos, e também o surgimento de pesquisas que ampliem o entendimento de docentes sobre o papel dos dados de input na geração de estruturas sintáticas (output) dentro de uma dada variedade linguística. E, com base nas contribuições de VanPatten (2003), é preciso investigar ainda mais que tipo de dado é considerado relevante para que haja um input adequado aos objetivos escolares.

Algumas indagações permanecem: a) a imitação e a repetição desempenham um papel na aquisição? b) os aprendizes desenvolvem maus hábitos se eles não forem corrigidos? c) o modo como se ensina faz diferença? d) o que faz algumas estruturas difíceis e outras fáceis de serem adquiridas? e) a idade faz mesmo diferença no aprendizado de língua? f) qual o melhor método para ensinar e aprender?

\section{Referências}

CARNIE, A. Syntax: a generative introduction. Oxford: Blackwell, 2002.

CHOMSKY, N. Syntatic Structures. The Hague: Mouton, 1957.

CHOMSKY, N. Aspects of the Theory of Syntax. Cambridge, MA: MIT Press, 1965.

CHOMSKY, N. Linguagem e mente: pensamentos atuais sobre antigos problemas. Brasília: Editora da UnB, 1998.

CHOMSKY, N. Arquitetura da linguagem. Bauru: EDUSC, 2008.

KATO, M. A. A gramática do letrado: questões para a teoria gramatical. In: MARQUES, M. A. et al. (Orgs.). Ciências da linguagem: trinta anos de investigação e ensino. Braga: CEHUM, 2005.

MIOTO, C. et al. Novo Manual de Sintaxe. 2.ed. Florianópolis: Insular, 2005.

VANPATTEN, B. From input to output: a teacher's guide to second language acquisition. New York: McGraw Hill, 2003. 